\title{
"Elasticity" Design of Modern Public Courtyard Space
}

\author{
Jianwu Ma 1, a, Yan Yang ${ }^{2, b}$ \\ ${ }^{1}$ Architecture College of Soochow University,china \\ ${ }^{2}$ Architecture College of Soochow University,china \\ a478646560@qq.com, b1143001915@qq.com
}

\begin{abstract}
Keywords: public courtyard, rainwater management, elasticity, design
Abstract. Rainwater management and design for impervious land is an important method of rainwater resource utilization and mitigation of negative impacts on surface runoff. Through the research and analysis of rainwater management cases in domestic and foreign courtyards, we can learn that these courtyards take the improvement of rainwater storage capacity as main purpose, meanwhile integrate the external overall water system into design to build up a sustainable water storage and row system , as well a system emulating water circulation in nature. In terms of some specific methods, domestic traditional courtyards pay more attention to the collection and utilization of rainwater. as long as we no longer consider the rainwater as waste can be discharged directly and manage it as valuable resource, we can keep it using our endless imagination. There are three main points to improve sponginess design in the courtyard space: detention and storage to absorb rainwater locally, input and output to regulate runoff and technology combining art to be multifunctional.
\end{abstract}

The development of sponge city in China is growing vigorously, despite some controversial points currently existing in the concept of sponge city, it is necessary to establish the social notion illustrated by this theory: strengthening urban rainwater management to make the city more flexible and adaptive in coping with the changing environment and disasters[1]. In our urban space, buildings, roads, squares, etc. which accounts for roughly $60 \%$ land surface of a city, are normally constructed with impermeable materials. Therefore, the management and design on these impermeable lands are the key factors to enable the city to operate as a sponge to coordinate the rainwater, which aims to reduce the peak value of overland runoff and stagger the peak periods. There are lots of impermeable public courtyards in urban spaces defined by settlements, business buildings, offices buildings and educational buildings, the "flexibility" design on those impermeable public courtyards proposes to improve their capacity of managing rainwater, make those courtyard spaces function as sponges to deal with the roof and overland runoffs, indeed, reduce the pressure of urban drainage systems meanwhile, reuse rainwater as resource and optimize the urban micro-climate.

\section{Characteristics of public courtyard}

The definition of "court" in traditional Chinese architecture is the open space in front of buildings. Additionally, illustrated by "Ci yuan (encyclopedic Chinese phrase dictionary)", "yard" is the space encircled by walls [2]. Generally, the courtyard is the open space defined by buildings. In consideration of spatial sequence, the courtyard is a buffering space between unlimited outdoor space and enclosed indoor space, it offers people a strong sense of private area. Contributed by the functions provided by courtyard space, people can engage with the nature in their private area and communicate with both the natural environment and friends, due to which courtyard is a sacred space in the minds of Chinese people [3]. However, result from the urbanisation and the increasing density of buildings, the enclosed private courtyard is barely seen in urban space, but the courtyard culture rooted in Chinese people's minds has never disappeared. The public outdoor space surrounded by modern buildings has spread all over the city and has become a place where people live, work and do business. The traditional private courtyard space has gradually evolved into the popular public courtyard space in urban space . 
The changes of the public courtyard's form, users, and functions attribute it several characteristics: 1. enclosed or semi-enclosed space defined by buildings; 2 . Frequent movements, a high percentage of hard paving; 3 . Has communicational and recreational functions, as well as pleasant landscape and abundant cultural connotation.

\section{The wisdom of rainwater management in domestic and foreign courtyard}

There are many domestic and foreign cases that courtyard make the garden "sponge" through rainwater management to maximize the absorption and utilization of rainwater storage. The usual method is through connecting a self-contained storage system in the courtyard and external overall water system to form a complete chain of rainwater management.

The rainwater management of Chinese traditional yard. In chinese traditional yard, patio is a

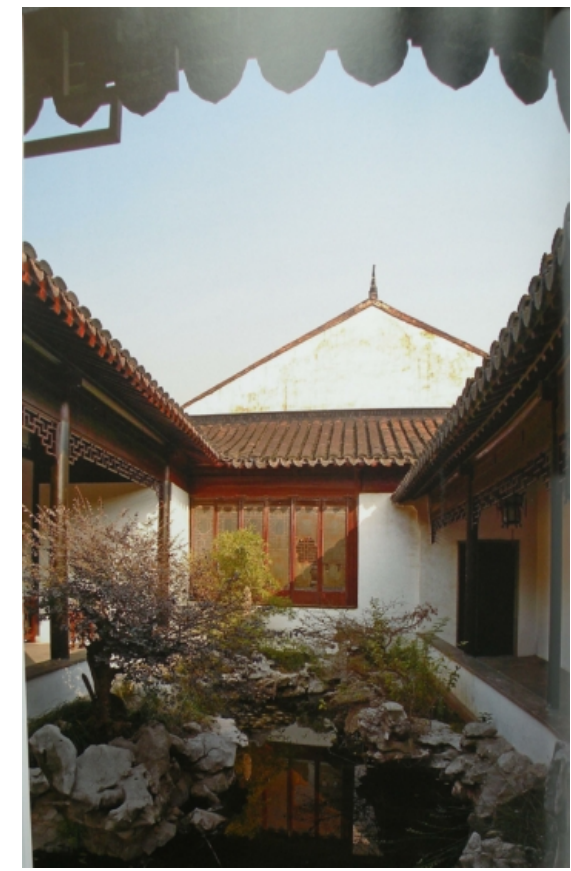

Figure 1. Traditional water yard

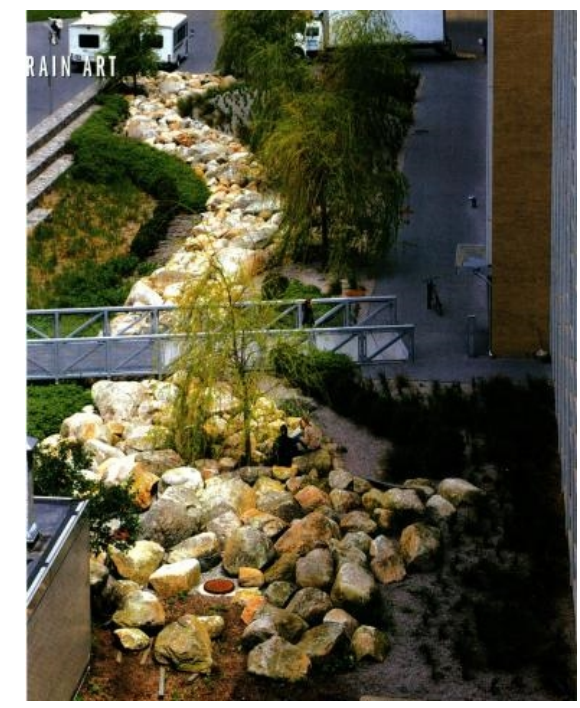

Figure 2. Ray and Maria Stata sunken garden at Massachusetts Institute of Technology pivotal part of rainwater management. The pavements of graits, gravels, tiles, potsherd, bricks and other permeable materials are flexibly used in the patio. And interspace among those materials creates good water permeablility and breathability, which keeps feet dry in rainy days and provide the natural water for plants. The permeable materials can not only reduce the ground runoff, but also recharge groundwater, moreover they can purify the water quality by soil and improve the microclimate too. 'Si Shui Gui Tang' is the typical example of this mode. The courtyard is surrounded by the house of which four sides have pitched roofs towards the patio. when it rains, rainwater flows into the pond through eaves gutters and catch basin around the patio. Finally rainwater goes into the rivers though ditches. So it is called 'Si Shui Gui Tang' [4].Besides 'Si Shui Gui Tang', the 'water yard' is focus on the pond.It collects the rainwater from roofs or introduces the external water system into the yard.The water flows through the walls and yards,despicting a picture of houses surrounded by the water and willows [5] ( Fig. 1).

In many areas of China, residents in courtyards build dispersed mini water systems by retaining, absorbing and reserving the rainwater locally. And then these systems are connected into a whole rainwater circulation system constructing a healthy water circulation in area.

Foreign experience. Rainwater management in developed countries carried out earlier, Therefore, many successful experiences and cases are worth learning from.

The Ray and Maria Stata Center at the MIT is a three-sided enclosed semi-enclosed public space, surrounded by teaching buildings (Fig. 2). The center of the space is a large sunken garden, which consists of a rainwater harvesting system above the ground and an underground detention and storage rainwater system.Rainwater is discharged from the roof and pavement into the garden through the water inlet with filtering device, filtering through plants and soil. At the same time, a small solar pump pumped water that had infiltrated the underground interception storage system into the wetland to irrigate the plants, while the rain infiltrated into the underground reservoir.

This cycle of repeated purification of rainwater, purified rain water can be recycled for flushing and 
sprinkler irrigation, excessive runoff was discharged to the urban drainage facilities[6].This design is outstanding in the use of rainstorms. Its various parts work in tandem to increase runoff to once every 25 years, reducing stormwater and sewer pressure, controlling non-point source pollution, and the rainstorm can be reused in landscapes and buildings. therefore excess runoff is pumped into the urban drainage system after a heavy rainstorm, These pumps work in conjunction with water tanks to control the rate of rainwater discharge, emissions and frequency. This innovative system addresses the issue of storm water quality, quantity, flow rate and frequency.

Located in the Pearl District in downtown Portland, 10th@ Hoyt is an inner courtyard of a 6-storey condominium with an area of $789 \mathrm{~m} 2$, despite the abundant of rainfall, rainwater management is still a necessary task in urban construction projects . The rectangular courtyard is surrounded by planting ponds, and the middle of the courtyard is provided with a rest space, rainwater retention pools, rest chairs, flower bowls and so on. What attracts people's attention is that there are copper downpipes on three sides of the courtyard connected to the ladder-type drains. Rain falls from a copper downpipe into a concrete step-shaped canals to create a charming water fall, which is then taken up by a stone-built stormwater plant and stored in a tank below it . The ground in the courtyard is all covered with permeable bricks. The designer sets up a water storage system under the water-permeable paving blocks. The rainwater is collected into the underground water storage system, which can hold about 15 cubic meters of runoff Over 30 hours. Overflow of stored runoff is slowly released to the urban stormwater system through a manually adjustable small valve. The reservoir's rainwater can be recycled back to the fountain in the courtyard. The system is similar to a "flexible" sponge that allows some sediment to settle for some time before it is drained.

The summary of sponginess design in domestic and foreign courtyards space. The sponginess design models of domestic traditional courtyard include: sloping roof, ditch, patio pond, water tank, sink, outlet, permeable flooring and other combinations to form a small independent system. The sloping roof leads the rainwater into the courtyard, and the ditches and sinks are used for the transportation and interception of the rainwater. Patio ponds, tanks and other deposits serve to collect and store rainwater. Permeable flooring allows rainwater that is not collected in time to penetrate into the ground, maintaining the soil respiration and water microcirculation in the hard underground soil. The discharge port is connected through the open ditch or culverts and the external system, ensuring that the courtyard can maintain normal rainwater storage of excess rainwater discharged to the peripheral water management system. Small courtyard not only stores and reuses the rainwater through rain guiding, interception, collection, transmission and storage overflow, but also slows down the runoff of external water and delayes the peak time of runoff so as to store large number of recycling rainwater through scattered interception and storage of families. In the process, the main use of natural water and water energy, combined with natural ecological concept and aesthetic vision, makes every design in detail, such as the patterned dripping eaves ditch, ponds, and the combination of plants and small rocks designed in the eaves, which combines management technology and art of rainwater by accident.

The sponginess design patterns of foreign modern courtyard include: open gutters, interception pool, bioretention ponds, water pump, reservoir, permeable pavement, and shunt. As the city drainage pipe disconnectes with downspout, rain is no longer directly discharged into the sewer, but is directed to the interception basin for temporary storage, then being transported to the bioretention pool and rain garden so as to store in reservoir through the vegetation and soil filtration. In the process of paving courtyard, it also adopts permeable pavement to make rainwater penetrate into the reservoir. The rainwater in the reservoir is often extracted by water pump into the rainwater garden repeatedly to permeate and filter, so as to achieve the aim of water quality control and resource utilization. Diversion facilities are important in the courtyard to connect urban pipelines and manage rainwater facilities. It consists of the overflow pipe, overflow pool and regulating valve. When rainfall exceeds the storage capacity, it will lead rainwater into the city pipelines taking advantage of shunt so as to avoid waterlogging . 
But in some specific methods at home and abroad, there exsits difference. The design of domestic traditional courtyard pays more attention to rainwater collection and utilization, however apart from these aspects, foreign modern courtyard attaches more importance to the "principle of land work", and purification and storage of soil and vegetation. Interception pool, bioretention ponds, reservoir and other pools are usually permeable, forming the hydrological circulation system together with ground permeable pavement. Meanwhile, it pays more attention to the use of external power as the water pump, in that the stored rainwater is extracted into greenland repeatedly in order to control water quality.

\section{The key points of sponginess design in modern courtyard}

It is difficult for modern courtyard, characterized by limited space, the high proportion of hard land,

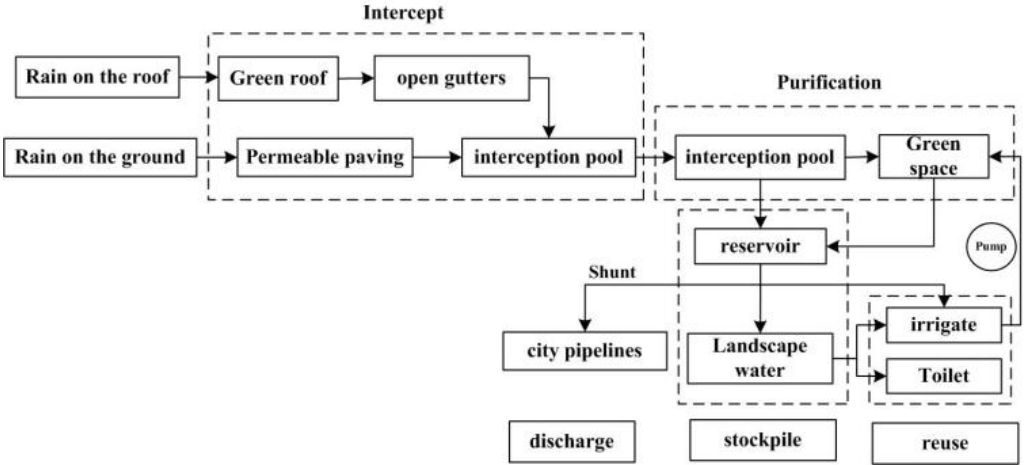

Figure 3. The circuit of lacunose filter layer in the courtyard and frequent activities of human, to store rainwater and control runoff in the whole area. However, as long as we change the idea that rainwater is used as a direct source of waste and regard it as a precious resource, we can unlimit the imagination to retain

rainwater. There are several points to imporve courtyard sponginess design.

Creating "lacunose filter layer" to store and absorb rainwater locally. "Storage and release according to demand" is the purpose of urban sponge design. The sponginess design of courtyard should first establish the idea of local rainwater management, and keep rainwater in the courtyard instead of directly discharging it as waste. It is the main method to improve the elasticity of the courtyard to create "lacunose filter layer" in the courtyard space. The "lacunose filter layer" in the courtyard is the whole space with infiltration and storage function. Because the penetration needs to

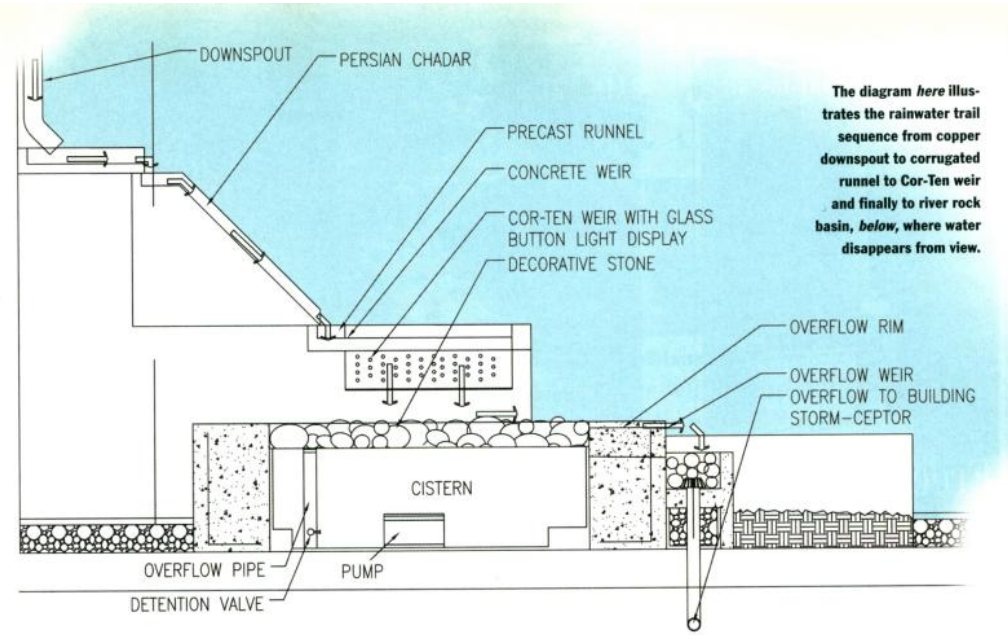

Figure4. Design of the Multi-Gap Filter Layer at the 10th@ Hoyt Residence in Portland be gradually completed in a certain period of time after interception, it is the core of "lacunose filter layer" to create space to intercept and store water, and design the infiltration structure of each space (Fig. 3). The original rainwater runoff contains a tremendous number of pollutants, which needs the preliminary purification through the first level "lacunose filter layer" including the process of simple filtration through green roof, open gutters, interception pool, bioretention ponds and permeable pavement. Interception pool and bioretention ponds can not contain water for more than 2 days in case of breeding mosquito to harm plants. Further purification need to be completed by greenland and reservoir, another level of "lacunose filter layer", 
which usually takes advantage of adsorption of vegetation and filtration and repeated penetration of soil. The first level works together with the second level to make the courtyard absorb rainwater to the most extent so as to manage rainwater runoff(Fig. 4).

Storaging and discharging to control runoff. The single sponge has limited storage capacity and needs to be connected with the larger one to cope with excess storage capacity. In order to improve the sponginess design of the courtyard, the complete rainwater storage and circulation system is needed to to maximize the consumption of rain. At the same time, in order to prevent the storm runoff from exceeding the storage capacity of the courtyard, it is necessary to communicate with the big circle outside the courtyard. It needs to apply power equipment and diversion facilities. Cyclic penetration and shunt management can maintain the courtyard sponge do its work. Interception and collection is only the first step of rainwater management, however, water quality control and resource utilization are the key to improve the elasticity of the courtyard. It can make use of power to let runoff flow and pump it back to the greenland. After repeated purification, when water quality reaching the standard, it can be further used as landscape water and recreational water, as well as for irrigating and flushing. Shunt design can not be ignored, which Includes the discharge diversion facilities, water overflow, overflow tank, control valve and other components to maintain the internal storage system and the external system of communication and convergence .

Combining technology and art to improve multifunction. Technology never exists alone. Public courtyard space is for public outdoor communication and leisure, which has higher requirements for the quality of landscape and culture. Flexible design needs to combine the public aesthetics and cultural pursuit, managing rainwater process with the landscape concept. The value of the foreign management facilities is evaluated from 12 aspects including aesthetic, biological, zoological , ecological, wildlife , entertainment, economic , technological , cultural, environmental , historical and the value of public relations. Rainwater management of courtyard should try to embrace above-mentioned value.

Modern cities advocate the idea of low impact development, and promote the use of decentralized small-scale facilities to control runoff from the source. The elastic design of the courtyard is the courtyard as a small rainwater management facility. Through the multi-objective design, the courtyard not only has the function of rainwater storage and runoff control, but also has the educational significance of environmental protection and cherishing the rainwater.

\section{Acknowledgements}

This work was financially supported by the National Natural Science Foundation of China (51168043), Photographs are provided by Dr. Stuart Echols, a professor of life at Penn State University Landscape School (PA, 16801).

\section{References}

[1] Sponge City Construction Technology Guide - Low Impact Development Rainwater System Construction, Housing Urban and Rural Construction Department

[2] Jiuying He, Ning Wang, Kun Dong editor, Yuan Ci, Commercial Press, 2015.11.

[3] Zhe-ming Hu, Qiu-shi Li, to explore the traditional living culture on the courtyard of a stigma in the interpretation of modern residential buildings, Huazhong Architecture, 2009,05.

[4] Xi Yuan Wang, Xiaowen $\mathrm{Xu}$, traditional residential buildings in the courtyard, Nanchang University, 2010.

[5] Jianwu Ma editor, Yunnan Minority landscape, China Forestry Publishing House 2006.06.

[6] Jianwu Ma, (US) Stuart Erxes, American Landscape Design in the Art of Rainwater Management, Chinese Garden, 2011.10 